OPEN ACCESS

Edited by:

Patrizia Rovere Querini, Vita-Salute San Raffaele

University, Italy

Reviewed by: Augusto Vaglio,

Università degli Studi di Parma, Italy Ralf J. Ludwig,

University of Lübeck, Germany

*Correspondence:

Wayel H. Abdulahad w.abdulahad@umcg.nt

Specialty section: This article was submitted to Inflammation, a section of the journal

Frontiers in Immunology

Received: 09 November 2017 Accepted: 05 February 2018

Published: 22 February 2018

Citation:

Hid Cadena R, Abdulahad WH, Hospers GAP, Wind TT, Boots AMH, Heeringa $P$ and Brouwer $E$ (2018)

Checks and Balances in Autoimmune Vasculitis. Front. Immunol. 9:315. doi: 10.3389/fimmu.2018.00315

\section{Checks and Balances in Autoimmune Vasculitis}

\author{
Rebeca Hid Cadena1, Wayel H. Abdulahad ${ }^{1,2 *}$, G. A. P. Hospers ${ }^{3}$, T. T. Wind ${ }^{3}$, \\ Annemieke M. H. Boots ${ }^{2}$, Peter Heeringa ${ }^{1}$ and Elisabeth Brouwer ${ }^{2}$
}

\begin{abstract}
${ }^{1}$ Department of Pathology and Medical Biology, University of Groningen, University Medical Center Groningen, Groningen, Netherlands, ${ }^{2}$ Department of Rheumatology and Clinical Immunology, University of Groningen, University Medical Center Groningen, Groningen, Netherlands, ${ }^{3}$ Department of Medical Oncology, University of Groningen, University Medical Center Groningen, Groningen, Netherlands
\end{abstract}

Age-associated changes in the immune system including alterations in surface protein expression are thought to contribute to an increased susceptibility for autoimmune diseases. The balance between the expression of coinhibitory and costimulatory surface protein molecules, also known as immune checkpoint molecules, is crucial in fine-tuning the immune response and preventing autoimmunity. The activation of specific inhibitory signaling pathways allows cancer cells to evade recognition and destruction by the host immune system. The use of immune checkpoint inhibitors (ICls) to treat cancer has proven to be effective producing durable antitumor responses in multiple cancer types. However, one of the disadvantages derived from the use of these agents is the appearance of inflammatory manifestations termed immune-related adverse events (irAEs). These irAEs are often relatively mild, but more severe irAEs have been reported as well including several forms of vasculitis. In this article, we argue that age-related changes in expression and function of immune checkpoint molecules lead to an unstable immune system, which is prone to tolerance failure and autoimmune vasculitis development. The topic is introduced by a case report from our hospital describing a melanoma patient treated with $\mathrm{ICls}$ and who subsequently developed biopsy-proven giant cell arteritis. Following this case report, we present an in-depth review on the role of immune checkpoint pathways in the development and progression of autoimmune vasculitis and its relation with an aging immune system.

Keywords: immune checkpoints, immune checkpoint inhibitors, immune-related adverse events, vasculitis, giant cell arteritis

\section{INTRODUCTION}

Age-associated changes in the immune system are thought to contribute to an increased susceptibility for autoimmune diseases. These changes include shifts in immune cell numbers, distribution, and function in conjunction with alterations in cell surface protein expression. One important class of surface proteins expressed on immune cells is immune checkpoint molecules, which regulate $T$ cell activation by relaying positive (costimulatory) and negative (coinhibitory) signals. The balance between the expression of coinhibitory and costimulatory molecules is crucial in fine-tuning the immune response and preventing autoimmunity. 
By exploiting the activation of specific inhibitory signaling pathways, cancer cells are able to evade recognition and destruction by the host immune system. Currently, several coinhibitory molecules are targeted by antibody-based antagonist biologicals in cancer immunotherapy. The rationale for this approach is that blockade of inhibitory checkpoints causes an unrestrained immune response allowing the host's tumor-specific T cells to attack the tumor cells. This immune checkpoint blockade strategy has proven to be very effective, producing long-lasting antitumor responses in multiple cancer types $(1-3)$.

Nevertheless, immune checkpoint therapy has its disadvantages. Blocking the inhibitory signaling pathways may unleash reactivity to healthy tissues, which consequently may result in inflammatory manifestations in patients receiving these agents, termed immune-related adverse events (irAEs) (3-6). These irAEs are often relatively mild, but more severe irAEs have been reported as well including several forms of vasculitis such as granulomatosis with polyangiitis (GPA) (7), lymphocytic vasculitis (8), and polymyalgia rheumatica/giant cell arteritis (9-11) (Table 1).

However, little is known about the role of immune checkpoints in vasculitis. In this article, we discuss the evidence that age-associated changes in expression and function of immune checkpoint molecules leads to an imbalance of the immune system. An immune system out of balance is prone to tolerance failure and the development of autoimmune vasculitis. The topic is introduced by a case report from our hospital describing a melanoma patient treated with immune checkpoint inhibitors (ICIs) and who subsequently developed biopsy-proven giant cell arteritis. This case study sets the stage for a more in-depth review on the role of immune checkpoint pathways in the development and progression of autoimmune vasculitis and its relation with the aging immune system.

\section{CASE VIGNETTE}

A 70-year-old man with a history of hepatitis A and who had a myocardial infarction in 2001 developed a melanoma of the skin of the left temple in 2015. He was diagnosed with stage IIIB

TABLE 1 | Reported cases of vasculitis developed after immune checkpoint inhibitor treatment.

\begin{tabular}{ll}
\hline Reference & Reported case \\
\hline van den Brom et al. (7) & $\begin{array}{l}\text { Granulomatosis with polyangiitis induced by immune } \\
\text { checkpoint inhibition ( } \alpha \text {-CTLA-4 and } \alpha \text {-PD-1) } \\
\text { Minor et al. (8) }\end{array}$ \\
Lymphocytic vasculitis of the uterus in a patient with \\
melanoma receiving ipilimumab
\end{tabular}

BRAF mutated melanoma and was treated with modified radical dissections including a parotidectomy, a neck dissection, and a free skin transplantation on June 8, 2015.

In August 2015, he started with adjuvant treatment in a double-blind study CA209-238 (Efficacy Study of Nivolumab Compared to Ipilimumab in Prevention of Recurrence of Melanoma after Complete Resection of Stage IIIb/c or Stage IV Melanoma (CheckMate 238); ClinicalTrials.gov number, NCT02388906) until April 2016. In April 2016, he was referred to the rheumatology and clinical immunology department with the following complaints: fatigue, low-grade fever with a temperature reaching $38.5 \mathrm{C}$, night sweats, and weight loss of $4 \mathrm{~kg}$ in 2 weeks. He had also experienced continuous pain for 4 weeks in his jaws and mastoid muscles. The right temple and masseter muscle were painful upon palpation, and his pain increased upon chewing. He had no hair pain or visual problems. He developed also new-onset pain and stiffness in his upper legs, neck, and shoulders. He had no pain or stiffness in his smaller joints, excluding a diagnosis fitting with arthritis.

On physical examination, he was fatigued, his blood pressure was 140/70 (upon measurement in both arms), his height was $1.78 \mathrm{~m}$, and his weight $62 \mathrm{~kg}$. His right temporal artery was painful, and his left temporal artery was not palpable (status after radical surgery). His shoulders and upper legs were painful upon movement. He had no infectious, gastrointestinal, or skin symptoms. His blood tests showed an elevated ESR of $93 \mathrm{~mm} / \mathrm{h}$, CRP of $52 \mathrm{mg} / \mathrm{L}$, a hemoglobin level of $7.8 \mathrm{mmol} / \mathrm{L}$ (in October 2015, before immune checkpoint treatment, these values were ESR of $37 \mathrm{~mm} / \mathrm{h}, \mathrm{CRP}$ of $1.6 \mathrm{mg} / \mathrm{L}$, and a hemoglobin level of $8.1 \mathrm{mmol} / \mathrm{L})$.

An ultrasound of the temporal and axillary arteries, a PET/ CT scan, and a temporal artery biopsy were performed. No halo fitting with GCA was observed upon US of his temporal and axillary arteries and muscles. The PET/CT did not show signs of large vessel vasculitis (LVV), myositis, infections, or metastasis, but did show some uptake surrounding both hips that would fit with a diagnosis of PMR. An additional MRI was performed, which did not show cerebral or leptomeningeal metastasis, and the masseter and temporal muscle and temporal and facial artery on the right side appeared to be normal. The ophthalmologist and the neurologist found no signs and symptoms that would fit the diagnosis of GCA and also ruled out trigeminal neuralgia.

The complaints of the patient were progressive, and his ESR and CRP remained high, while his right temporal artery increased in size and remained painful upon palpation. On May 23, 2016, the patient underwent a temporal artery biopsy from his right temporal artery, which revealed a transmural inflammation of the adventitial, medial, and intimal layers of the temporal artery with a fragmented internal and external lamina elastic, diagnostic for GCA (Figure 1). On May 24, the patient started with highdose prednisolone $(60 \mathrm{mg}$ /day), which was tapered to $30 \mathrm{mg}$ /day on May 25 (due to severe side effects) and gradually tapered to $2.5 \mathrm{mg}$ /day on November 3, 2016. Disease activity of GCA was monitored according to the BSR definition that a disease relapse should be suspected in patients with a return of symptoms of GCA, ischemic complications, or unexplained constitutional or 


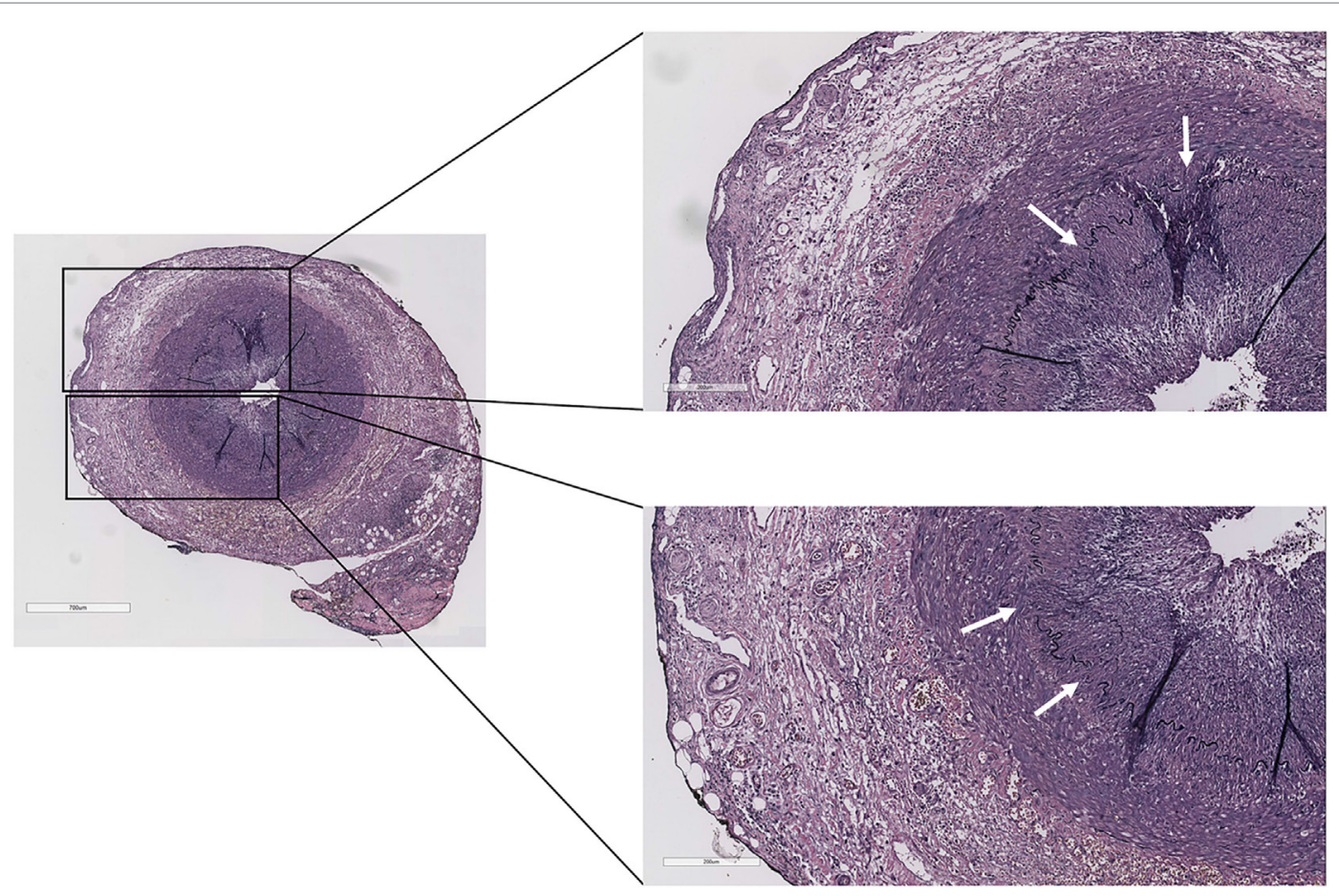

FIGURE 1 | Temporal artery biopsy of the case report patient showing transmural inflammation of the adventitial, medial, and intimal layers with a fragmented internal and external lamina elastic (white arrows) (Verhoeff-Van Gieson staining).

polymyalgic symptoms. (Relapse is usually associated with an increase in erythrocyte sedimentation rate/C-reactive protein, but may occur with normal inflammatory markers.)

Unfortunately, in October 2016, he had developed metastasized melanoma (lymph nodes and lung), and his previous adjuvant treatment was deblinded (not allowed to mention in this article nivolumab or ipilimumab as the study is not yet deblinded). On November 3, he started with a different checkpoint inhibitor. $\mathrm{He}$ had some persistent smoldering low-grade GCA complaints, which increased on this treatment. The complaints consisted of a headache on his left side and pain and stiffness in his neck and upper legs, and he had a painful temporal artery on his left side. The ESR of $37 \mathrm{~mm} / \mathrm{h}$ and CRP of $7 \mathrm{mg} / \mathrm{dL}$ were slightly increased, suggesting a GCA relapse. The prednisolone dose was increased to $10 \mathrm{mg} /$ day. Infusions with checkpoint inhibition were continued, and he was advised to take an increased prednisolone dose of $20 \mathrm{mg}$ at day 2 and 3 after these infusions.

In May 2017, he still had signs and symptoms that fit with active GCA, especially jaw complaints upon chewing but no headache. The ESR was $4 \mathrm{~mm} / \mathrm{h}$ and CRP was $<0.3 \mathrm{mg} / \mathrm{dL}$. He was advised to taper the prednisone to $7.5 \mathrm{mg} /$ day to control the GCA without giving too much immunosuppression. A schematic representation of GCA development induced by immune checkpoint blockade is given in Figure 2.

The case described above is a prime example of an adverse consequence upon immune checkpoint therapy, illustrating that removing the natural brakes of the immune system may lead to a breach of tolerance and development of autoimmunity, such as LVV in this example (Figure 3). In this case, the patient was treated with in total two ICIs. ICIs are FDA-approved drugs in the treatment of advanced melanoma. Ipilimumab was the first checkpoint inhibitor approved by the FDA in 2011 for the treatment of advanced melanoma (12), and it showed improved efficacy and survival benefits compared to other chemotherapeutic agents (13). PD-1 inhibition with pembrolizumab and nivolumab also has proven to be effective in advanced melanoma (14-17) and was approved by the FDA in 2014.

Besides anti-PD-1 agents, the FDA has also recently approved antiprogrammed death-ligand 1 (PD-L1) agents for the treatment of patients with several types of cancer $(18,19)$. In the coming years, the approval of new ICIs or a combination of checkpointtargeting agents that are currently under investigation in oncology clinical trials is expected. Approval of these drugs will translate into an increased use of immunotherapies, prompting the investigation of the underlying mechanisms of immune checkpoint regulation to avoid unwanted adverse events such as the one presented in the case above.

Although there is an increased awareness of the more common irAEs upon immune checkpoint therapies, rare but severe and potentially life-threatening autoimmune manifestations, such as vasculitis, should be taken into account when evaluating the benefit of tumor destruction and the associated risks of immunotoxicity. Some of the toxicities related to immune checkpoint therapy reported in multiple studies are summarized in Table 2 $(16,20,21)$. The reported rate for the more common irAEs, which involve the skin, gastrointestinal system, and endocrine system 


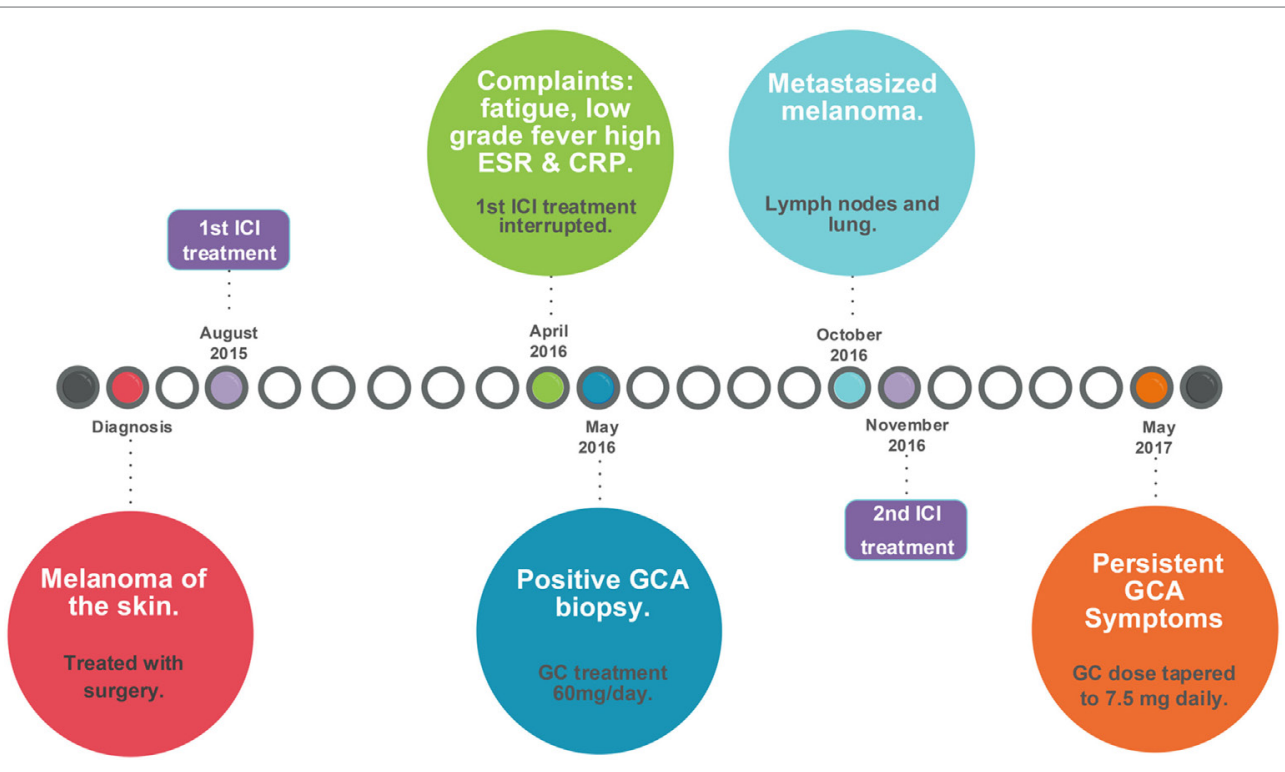

FIGURE 2 | Timeline of events leading to the development of GCA induced by checkpoint immunotherapy. CRP, C-reactive protein; ESR, erythrocyte sedimentation rate; GC, glucocorticoids; GCA, giant cell arteritis; ICI, immune checkpoint inhibitor. Surgery included a modified radical dissections including a parotidectomy, a neck dissection, and a free skin transplantation on June 8, 2015, for stage Illb melanoma, which was followed by inclusion in the CA209-238 study [Efficacy Study of Nivolumab Compared to Ipilimumab in Prevention of Recurrence of Melanoma After Complete Resection of Stage Illb/c or Stage IV Melanoma (CheckMate 238); ClinicalTrials.gov number, NCT02388906].

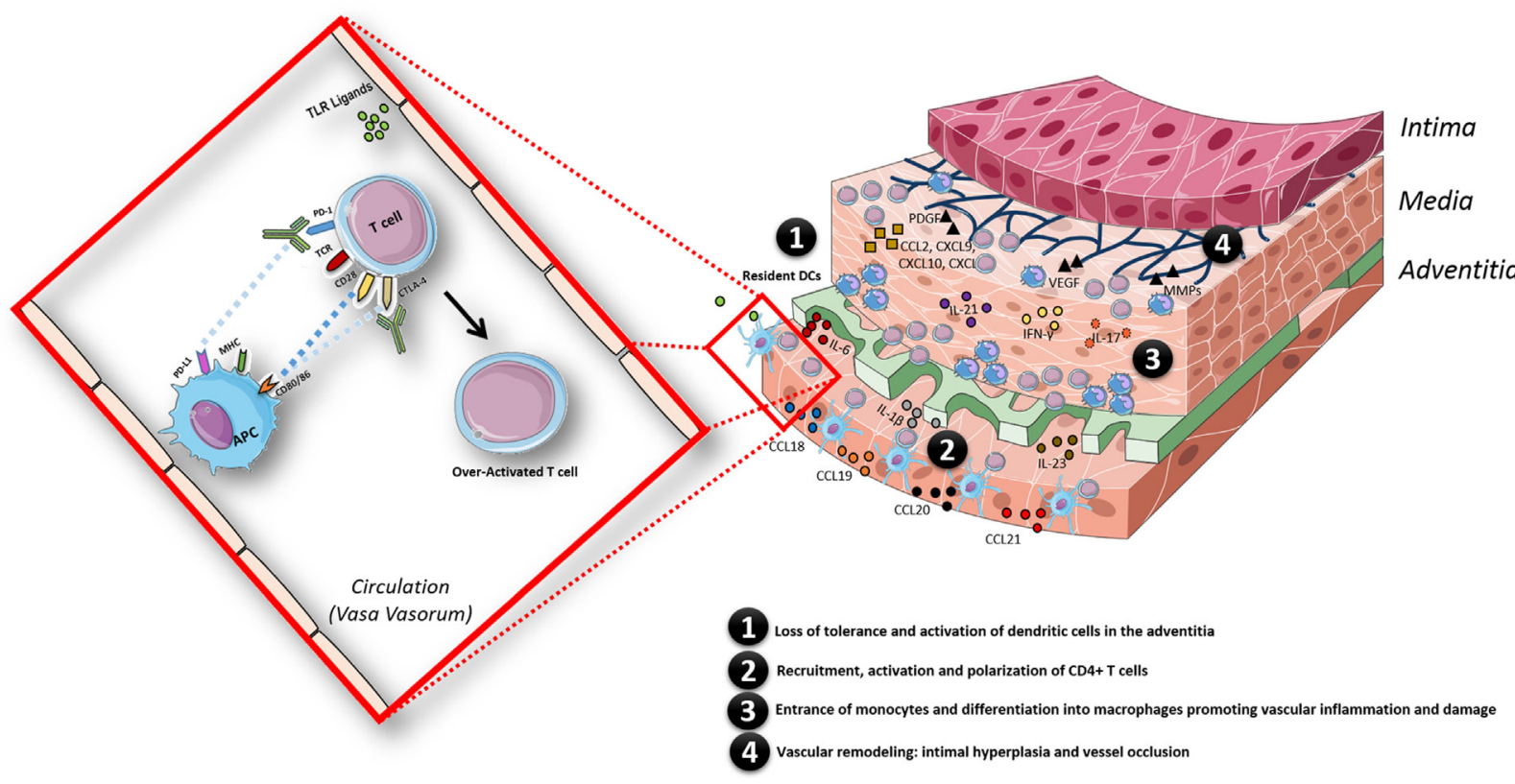

FIGURE 3 | Schematic model of the pathogenesis of giant cell arteritis, facilitated by the state of chronic inflammation in aged individuals and in addition by an overactivated immune system triggered by immune checkpoint inhibitor treatment. The inflammatory response in the arterial wall is initiated when resident dendritic cells (DCs) sense danger signals via pattern recognition receptors such as toll-like receptors. Activated DCs produce chemokines (CCL18, CCL19, CCL20, and CCL21), which recruit CD4+ T cells; once recruited in the arterial wall, CD4+ T cells are activated by DCs presenting still undefined antigen(s). The presence of pro-inflammatory cytokines (IL-6, IL-1 $\beta$, IL-23, IL-18, and IL-12) in the microenvironment polarizes CD4+ T cells toward Th1 and Th17 cells, which produce large amounts of IFN- $\gamma$ and IL-17. Eventually, monocytes enter the vascular wall and differentiate into macrophages promoting vascular inflammation by secreting cytokines and vascular damage via secretion of matrix metalloproteinases (MMPs). Macrophages, giant cells or injured VSMC also produce growth factors such as platelet-derived growth factor (PDGF) and vascular endothelial growth factor (VEGF). This results in vascular remodeling: intimal hyperplasia and vessel occlusion. The whole process is facilitated by a state of chronic inflammation as observed in aged individuals and additionally by an overactivated immune system triggered by immune checkpoint therapy treatment in this case. 
TABLE 2 | Frequency of selected immune-related adverse events associated with immune checkpoint inhibitor treatment. ${ }^{a}$

\begin{tabular}{llcc}
\hline Type of disorder & $\begin{array}{c}\text { Anti-CTLA-4 } \\
\text { (ipilimumab) }\end{array}$ & $\begin{array}{c}\text { Anti-PD-1 } \\
\text { (nivolumab or } \\
\text { pembrolizumab) }\end{array}$ & $\begin{array}{c}\text { Combination } \\
\text { therapy }\end{array}$ \\
\hline
\end{tabular}

\begin{tabular}{|c|c|c|c|}
\hline \multicolumn{4}{|l|}{ Skin (rash) } \\
\hline Robert et al. (16) & 14.5 & 14.7 & $N R$ \\
\hline Postow et al. $(20,37)^{c}$ & 26 & NR & 41 \\
\hline Larkin et al. $(21)^{d}$ & 32.8 & 25.9 & 40.3 \\
\hline Range & $15-33 \%$ & $15-26 \%$ & $40-41 \%$ \\
\hline \multicolumn{4}{|c|}{ Gastrointestinal (diarrhea) } \\
\hline Robert et al. $(16)^{b}$ & 22.7 & 16.9 & NR \\
\hline Postow et al. $(20,37)^{c}$ & 37 & NR & 45 \\
\hline Larkin et al. (21) d & 33.1 & 19.2 & 44.1 \\
\hline Range & $23-37 \%$ & $17-19 \%$ & $44-45 \%$ \\
\hline \multicolumn{4}{|c|}{ Endocrine (hypothyroidism) } \\
\hline Robert et al. (16) ${ }^{\mathrm{b}}$ & 2 & 10.1 & NR \\
\hline Postow et al. $(20,37)^{c}$ & 15 & NR & 16 \\
\hline Larkin et al. (21) d & 4.2 & 8.6 & 15 \\
\hline Range & $2-15 \%$ & $9-10 \%$ & $15-16 \%$ \\
\hline \multicolumn{4}{|l|}{ Others (arthralgia) } \\
\hline Robert et al. (16) & 5.1 & 9.4 & NR \\
\hline Postow et al. $(20,37)^{c}$ & 9 & $N R$ & 11 \\
\hline Larkin et al. (21) & 6.1 & 7.7 & 10.5 \\
\hline Range & $5-9 \%$ & $8-9 \%$ & $10-11 \%$ \\
\hline
\end{tabular}

avalues are the percentage of treated patients who experienced adverse events of any grade (based on the common terminology criteria for adverse events grading system). b/pilimumab ( $N=256)$, anti-PD-1 agent used: pembrolizumab ( $N=278)$.

Ipilimumab ( $N=46)$; combination therapy used: nivolumab plus ipilimumab $(N=94)$. I/pilimumab ( $N=311)$; anti-PD-1 agent used: nivolumab ( $N=313)$; combination therapy used: nivolumab plus ipilimumab $(N=313)$.

$N R$, not reported.

are comparable when using only one ICI, but the reported rate for these irAEs significantly increases when a combination of therapies is used. For those types of disorders that are not as common, the reporting rate is very low, even when combination therapy is used. The frequency of autoimmune complications may be underestimated due to the fact that follow-up in clinical trials is usually short, and the development of autoimmune toxicities can have a delayed onset (22).

To better understand the mechanisms of action of ICIs and the adverse consequences derived from their use, it is essential to consider the various immune functions that these checkpoints control; this issue is addressed in the following sections.

\section{COINHIBITORY CHECKPOINT PATHWAYS}

The two inhibitory checkpoint pathways that have been most widely studied in oncology are the CTLA- 4 and PD- 1 pathways. Immune responses are negatively regulated by these pathways at different levels and by different mechanisms.

\section{CTLA-4 Pathway}

The ability of the immune system to protect from harm and prevent unnecessary tissue injury is maintained by a delicate balance between costimulatory and coinhibitory molecules. One example of this delicate balance is the interaction between the coinhibitory molecule CTLA-4 and its counterpart, the costimulatory molecule CD28. Both CD28 and CTLA-4 are expressed on $\mathrm{T}$ cells and control the early stages of $\mathrm{T}$ cell activation (23-25). Once antigen recognition occurs through engagement of the $\mathrm{T}$ cell receptor (TCR) with the cognate antigen-MHC complex, presented by antigen-presenting cells (APCs), CD28 binds to CD80 and CD86; this binding strongly amplifies TCR signaling to activate $\mathrm{T}$ cells (25-28). Within $48 \mathrm{~h}$ of activation, expression of CTLA-4 is upregulated on activated T cells (3). As CD28 and CTLA-4 share identical ligands, the latter dampens T cell activation by outcompeting the former in binding to CD80 and CD86 $(24,29-31)$. CTLA-4 can further decrease activation by sending a signal to APCs to reduce CD80/86 expression (32) and secrete indoleamine 2,3-dioxygenase (IDO), an enzyme that catalyzes tryptophan degradation (33), disabling T lymphocytes to proliferate due to tryptophan shortage (34). Activated CD8+ T cells also express CTLA-4, which suppresses helper T cell activity and enhances the immunosuppressive activity of regulatory $\mathrm{T}$ (Treg) cells (35). Treg cells constitutively express CTLA-4, which on the one hand leads to Treg cell proliferation and enhanced production of IL-35, IL-10, TGF- $\beta$, and IDO. On the other hand, on effector T (Teff) cells, CTLA-4 engagement causes a decreased activation and proliferation $(6,36)$.

Collectively, as CTLA-4 regulation takes place early in the process of T cell activation and augments Treg function, it is likely that its blockade leads to an unrestrained non-specific activation of the immune response. This broad activation may explain the wide variety of adverse events seen when this pathway is blocked $(25,37)$

\section{PD-1 Pathway}

Although both CTLA-4 and PD-1 are negative checkpoints, PD-1 exerts its function at different levels and via different mechanisms. Upon engagement to either PD-L1 (also known as CD274 and B7-H1) or programmed death-ligand 2 (PD-L2; also known as CD273 and B7-DC), tyrosine phosphorylation of the PD-1 cytoplasmic domain occurs and tyrosine phosphatase SHP-2 is recruited, resulting in disruption of the TCR signaling cascade (38-41). These effects ultimately block T cell proliferation, diminish cytokine production and cytolytic function, and impair T cell survival $(3,42,43)$. The cellular expression of PD-1 is broader than that of CTLA-4; for example, B cells and natural killer cells also express and upregulate PD-1 upon activation (25, 44), thereby temporarily dampening their effector functions (39). Another important subset of T cells that highly expresses PD-1 is Treg cells, and it has been demonstrated that PD-1 ligation on these cells enhances their immunosuppressive activity $(43,45)$. Both the PD-L1 and PD-L2 ligands are expressed on APCs and other hematopoietic and non-hematopoietic cell types (46).

In preclinical models, $\mathrm{PD}-1 / \mathrm{PD}-\mathrm{L} 1$ pathway inhibition also generates antitumor activity and enhances autoimmunity (47). However, the autoimmune phenotypes of mice with PD-1 or CTLA-4 deficiencies are different. CTLA-4 deficiency results in a more severe, non-specific autoimmune phenotype as it affects both cell-intrinsic activities (on Teff cells) and cell-extrinsic activities (on Treg cells) (48). By contrast, PD-1 deficiency results in a mild and chronic autoimmune phenotype since it is mainly manifested as cell-intrinsic alterations of Teff cells $(3,48)$. Since 
PD-1 activation suppresses the immune response during the effector phase of $\mathrm{T}$ cell activation and upon repeated antigen exposure, PD-1 blockade probably targets a more restricted assortment of T cells than CTLA-4 blockade (3).

\section{LESSONS LEARNED FROM ONCOLOGY}

The cancer immunity cycle described by Chen and Mellman in 2013 has become a useful framework for immunotherapy research. Briefly, the authors refer to seven steps, which need to be initiated and allowed to proceed and expand iteratively for an anticancer immune response to effectively kill cancer cells. These steps involve: step 1: the release of cancer antigens, step 2: presentation of those antigens through APCs and dendritic cells (DCs), step 3: T cell priming and activation within the lymph node, step 4: $\mathrm{T}$ cell trafficking to tumors, step 5: T cell infiltration into the tumor, step 6: recognition of cancer cells by $\mathrm{T}$ cells, and finally, step 7: cancer cell killing, which restarts the cycle (49). In each step described above, as in all of the immune system processes, checks and balances are required to perform optimally, which in cancer patients are ablated due to cancer's many strategies to evade recognition by the host immune system. Obstacles encountered in one or several steps of the cancer-immunity cycle are the target of immunotherapy; therefore, combination of approaches with therapies stimulating various and different steps of the cycle may result in higher response rates (50) and consequently more irAEs.

\section{Effect of Immunotherapies on Checkpoint Molecule Expression and Function}

In cancer patients, anti-CTLA-4 treatment lowers the threshold required for $\mathrm{T}$ cell activation, which leads to an expansion of circulating low-avidity $\mathrm{T}$ cells (51), resulting in a sustained immune response. In addition, it has been shown that anti-CTLA- 4 therapy promotes antitumor activity by a selective reduction of intratumoral Treg via Fc- $\gamma$ R-mediated depletion (52), impairing Treg cell survival and function along with concomitant activation of Teff cells $(35,53)$. In addition, Th17 cells, which are implicated in many autoimmune and chronic inflammatory disorders (54) and in tumor eradication (55) processes, are also affected by CTLA-4 blocking. In cancer patients, it has been demonstrated that upon anti-CTLA-4 treatment, the number of circulating Th17 cells in patients increases, especially in those patients who developed clinically relevant inflammatory and autoimmune toxicities (56).

Recently, Wei et al. confirmed that distinct cellular mechanisms underlie anti-CTLA-4 and anti-PD-1 checkpoint blockade. The authors concluded that both checkpoint blockade therapies targeted only specific tumor-infiltrating exhausted-like CD8 $\mathrm{T}$ cells and that the effect of these agents primarily differed in the expansion of inducible costimulator (ICOS) + Th1-like CD4 effector cells induced by the anti-CTLA-4 agent (57). Furthermore, additional studies in cancer patients show that after targeting CTLA-4 with ipilimumab, responding patients have increased ICOS + T cells $(58,59)$. Several research groups have reported that there appears to be a compensatory upregulation of alternative checkpoints following immune checkpoint blockade (60-62). Very recently, a study by Gao et al. demonstrated that the inhibitory immune checkpoint molecules PD-L1 and V-domain Ig suppressor of $\mathrm{T}$ cell activation are both upregulated in $\mathrm{CD} 4+$ and CD8+ T cells and CD68+ macrophages of prostate cancer patients in response to ipilimumab therapy (62). The upregulation of alternative checkpoints as a compensatory mechanism might explain the lack of response or partial tumor regression observed in preclinical models $(60,61)$ and in cancer patients when treated with anti-CTLA-4 or anti-PD-1 monotherapy $(16,62,63)$.

Such compensatory mechanism by which the immune system strives toward balance is supported by increasing evidence, indicating that basic signaling mechanisms of several immune checkpoint pathways are intertwined with each other forming a complex network that regulates the immune response. Kamphorst et al. found that CD28 signaling is essential for T cells to effectively respond to PD-1 blockade during chronic viral infection (64). Through conditional gene deletion, they showed a cellintrinsic requirement of CD28 for CD8 T cell proliferation after PD-1 therapy (64). Moreover, Hui et al. reported that CD28 is strongly preferred over the TCR as a target for dephosphorylation by PD-1-recruited SHP-2 phosphatase, revealing that signaling through PD-1 occurs mainly by inactivating CD28 signaling (65). These data suggest that there is a broader interaction between PD-1 and CD28 than previously assumed, and such interaction might serve as a general mechanism for enhancing normal $\mathrm{T}$ cell responses and revitalizing exhausted T cells (66).

The unprecedented clinical success of cancer immunotherapy and the subsequent development of irAEs seen with these therapies have enabled researchers to study the underlying mechanisms of the early stages of autoimmunity. The expression of inhibitory receptors has been reported to be altered in many autoimmune diseases $(67,68)$, which suggests that signaling by inhibitory receptors is involved in the etiology of autoimmune diseases $(67,69)$. However, whether defective expression and/or function of immune checkpoints is a cause or consequence of autoimmunity and the ensuing autoimmune diseases is largely unknown. One factor that may be involved is age since aging is known to alter many aspects of the immune system and increases the susceptibility for the development of autoimmune diseases.

\section{IMPACT OF AGING AND IMMUNOSENESCENCE ON CHECKPOINT MOLECULE EXPRESSION}

As a result of aging-related changes in the immune system, the human body becomes more susceptible for developing cancer, autoimmune diseases, infections, and cardiovascular diseases (70-73). Aging impacts both the innate and adaptive constituents of the immune system, which lead to a dysregulated immune and inflammatory response contributing to the increased incidence of chronic immune-mediated diseases in elderly individuals (74).

The immune system of aged people shows an accumulation in the frequency of highly differentiated $\mathrm{T}$ cells of which, due to a greater homeostatic stability, CD4+ $\mathrm{T}$ cells are being less affected by the age-associated phenotypic and functional changes than CD8+ T cells $(75,76)$. These changes include loss of the cell surface costimulatory molecules CD27 and CD28, CD8+ 
T cells losing CD28 first followed by CD27 and vice versa for CD4+ T cells (77). Loss of the costimulatory molecule CD28 is a hallmark of the age-related decline of $\mathrm{T}$ cell function, which has been associated with a less-efficient capability to mediate immune responses in old individuals (78).

In addition to the loss of costimulatory molecules, there is an increase in the expression of inhibitory receptors, which adds to $\mathrm{T}$ cell dysfunction during aging (79). The expression of the inhibitory checkpoint molecule, CTLA-4 increases with age (80), whereas the expression of PD-1 is considered to be dependent on viral status rather than age and may also serve as a useful marker on viral-specific CD8+ T cells to indicate the degree of T cell exhaustion (41). In chronic viral infections and tumor microenvironments, $\mathrm{PD}$-1-expressing exhausted cells lose their ability to produce IFN- $\gamma$ and TNF- $\alpha$ and therefore become dysfunctional (81-83).

The age-related changes and deterioration of the immune system have been linked to immunosenescence (84), a term referring to the continuous remodeling of lymphoid organs, which leads to reduced immune function in elderly people (85). One of the major factors that fuels immunosenescence appears to be the lifelong chronic antigen load $(86,87)$ including leakage of microbial products from the gut to the circulation, resulting in continuous stimulation of both innate and adaptive immunity. Altogether, these changes lead to a chronic pro-inflammatory state favoring the development of age-associated (auto) inflammatory diseases (88).

\section{ROLE OF IMMUNE CHECKPOINTS IN THE DEVELOPMENT OF IMMUNE-MEDIATED VASCULITIS}

Vasculitides are a heterogeneous group of inflammatory disorders characterized by inflammation of the blood vessel wall. The clinical manifestations are determined by the localization, the type of vessel involved, and the nature of the inflammatory process (89). The Chapel Hill nomenclature classifies non-infectious vasculitides mainly according to the type of vessel affected: LVV, medium vessel vasculitis (MVV), and small vessel vasculitis (SVV). LVV affects the aorta and its main branches, and the primary vasculitides in this group are GCA and Takayasu arteritis. MVV affects the main visceral arteries and its branches; examples of diseases in this group are polyarteritis nodosa and Kawasaki disease. Finally, SVV is further subdivided into antineutrophil cytoplasmic antibody (ANCA)-associated vasculitis (AAV) and immune complex SVV. The major clinicopathologic variants of AAV are GPA, microscopic polyangiitis (MPA), and eosinophilic granulomatosis with polyangiitis (EGPA) (90).

Antineutrophil cytoplasmic antibody-associated vasculitis is predominantly disease of the elderly. The incidence of AAV increases with age, peaking in those aged 65-74 years (91-93). A hallmark of the AAV is the presence of autoantibodies directed at neutrophil cytoplasmic constituents (ANCA) $(94,95)$. The target antigens of ANCA in the AAV are proteinase 3 (PR3) and myeloperoxidase (MPO) where GPA is primarily associated with PR3-ANCA and MPA and EGPA with MPO-ANCA.
The immunopathological model of AAV in the acute effector phase is centered around ANCA and pro-inflammatory stimuli, most likely of infectious origin, which synergize in initiating a destructive inflammatory process $(94,95)$. A central event in this process is ANCA-mediated neutrophil activation resulting in the generation of reactive oxygen species (ROS), degranulation and cytokine production, a process that is greatly facilitated by minor (pro-)inflammatory stimuli that prime the neutrophil to interact with ANCA. Upon disease progression, acute vasculitis lesion transform into lesions that predominantly contain macrophages and T cells.

Although data on checkpoint expression in AAV patients are scarce, Wilde et al. reported increased expression of PD-1 on circulating $\mathrm{T}$ helper cells of GPA patients, whereas $\mathrm{T}$ cells in renal lesions mostly lacked PD-1 (96). The authors found that PD-1 expression was positively correlated with expansion of memory $\mathrm{T}$ cells, CD28 ${ }^{\text {null }} \mathrm{T}$ cells, as well as with $\mathrm{T}$ cell activation. In addition, PD-1 expression was found to be enhanced on pro-inflammatory IFN- $\gamma$ T cells in GPA patients. These observations suggested that increased PD-1 expression on T cells might counterbalance persistent T cell activation (96).

Furthermore, Slot et al. analyzed single-nucleotide polymorphisms in the genes encoding PD-1 and CTLA-4 describing SNP frequencies in GPA patients that could explain hyperreactivity of T cells in these patients (97). Interestingly, in 2016, our group reported for the first time the development of GPA after sequential immune checkpoint inhibition with anti-CTLA-4 and anti-PD-1 treatment, as well as the first report of vasculitis observed after anti-PD-1 treatment (7). In that case report, we hypothesized that anti-CTLA-4 treatment induced PR3-ANCA production, which created the conditions necessary for the development of GPA, a process that was rapidly amplified by anti-PD-1 treatment (7).

GCA, the most common vasculitis after 50 years of age (98, 99 ), is thought to be caused by both changes in the aging vessel wall and in the immune system. The immunopathological model of GCA can be divided into four phases: in phase 1, there is a loss of tolerance (cause unknown) and activation of resident DCs of the adventitia, which results in the recruitment, activation, and polarization of CD4+ T cells (phase 2). Once recruited and activated in the arterial wall, the presence of pro-inflammatory cytokines (e.g., IL-12, IL-18, IL-23, IL-6, and IL-1 $\beta$ ) in the microenvironment polarizes CD4+ T cells toward Th1 and Th17 cells. Th1 and Th17 are responsible for the production of large amounts of IFN- $\gamma$ and IL-17, respectively, which ultimately leads to the recruitment of CD8+ T cells and monocytes (phase 3 ). Vascular remodeling (phase 4) starts when the IFN- $\gamma$-stimulated monocytes differentiate into macrophages and vascular smooth muscle cells differentiate into myofibroblasts producing IL-6, IL-1 $\beta$, TNF- $\alpha$, and vascular endothelial growth factor (99). This amplifies the local inflammatory response causing the release of toxic mediators for the arterial tissue such as ROS and matrix metalloproteinase, which eventually results in remodeling processes leading to intima proliferation and vascular occlusion $(99,100)$.

Accumulating evidence, including the case herein reported, points to an important role of immune checkpoints in the development of GCA. This is also emphasized by the demonstrated efficacy of abatacept; a new treatment for GCA $(99,101)$. This 
agent is a soluble fusion protein consisting of the ligand-binding domain of CTLA-4 and the Fc region derived from IgG1. CTLA4-Ig binds to the APC B7 (CD80/86) molecule, thereby blocking B7 interaction with the CD28/CTLA-4 receptor on the T cell (102). By contrast, ipilimumab antagonizes the action of CTLA-4, thus enhancing immune reactivity by releasing this immunosuppressive checkpoint.

The involvement of immune checkpoints in the development of autoimmune side events is further supported by evidence from oncology, which shows that both CTLA-4 and PD-1 blockade result in enhanced Th17 cell responses and impaired Treg survival and function $(52,53,56,103)$. In addition, PD- 1 blockade results in enhanced Th1 cell responses and increased production of cytokines such as IL-6 and IL-17 (103). This T cell functional flexibility and plasticity might be one of the mechanisms involved in the induction of autoimmune side effects (6).

In addition to CTLA-4 involvement in GCA, a recent study indicates that the immunoprotective $\mathrm{PD}-1 / \mathrm{PD}-\mathrm{L} 1$ signaling pathway is affected as well. The study showed that tissue-residing DCs of GCA patients were low in PD-L1, whereas the majority of vasculitic T cells at the site of inflammation expressed PD-1 (104). Moreover, the in vivo vasculitogenic potential of PD-1 blockade was demonstrated using a humanized mouse model system of vasculitis, the Human Artery-Severe Combined Immunodeficiency Mouse Chimera model. Briefly, human axillary arteries were engrafted into NSG mice, and PBMCs from GCA patients or healthy individuals were adoptively transferred into the chimeras; chimeras were randomly assigned to treatment with PD-1 antibody or isotype control antibody. In this model, the authors confirmed that inhibiting PD-1/PD-L1 interaction enhanced tissue inflammation as GCA PBMCs but not healthy PBMCs were able to induce vasculitis. More specifically, PD-1 blockade enabled very few healthy $\mathrm{T}$ cells to enter the vascular wall, while PBMCs from GCA patients induced vessel wall inflammation. These observations suggested that $\mathrm{T}$ cells from GCA patients are especially vulnerable to PD-1 blockade (104, 105).

Zhang et al. demonstrated that in GCA a breakdown in PD-1/ PD-L1 checkpoint resulted in unleashed vasculitic immunity and that such breakdown was responsible for the pathogenic remodeling of the inflamed arterial wall (104). The authors reported that PD-1 blockade gave rise to T cells producing IFN- $\gamma$, IL-17, and IL-21, which sustained multifunctional effector functions associated with the rapid outgrowth of hyperplastic intima and the induction of microvascular neoangiogenesis (104). Worthy of note, T cells producing IFN- $\gamma$, IL-17, and IL-21 play an important role in GCA and contribute to the pathogenesis of the disease (106, 107). Furthermore, PD-1 blockade biased T cells toward increased T-bet and RORC expression and diminished FoxP3 expression (104).

\section{CONCLUDING REMARKS}

During the past decade, the introduction of ICIs has revolutionized cancer therapy and has proven to be a very effective strategy in inducing durable antitumor responses in multiple cancer types. Increasing evidence supports the idea that immune checkpoints cannot be regarded as separate pathways but as a complex network functioning in concert to maintain the delicate balance in the immune system. However, despite the clear therapeutic benefit, it is undeniable that the induction of irAEs is a serious disadvantage. It has become clear that data on safety of immune checkpoint therapies need further study in elderly individuals (85). It might be that the patient's age is a relevant risk factor for irAEs (108) as the immune system of an elderly person is likely to demonstrate age-associated changes in checkpoint expression and function, which may be altered due to the chronic, lowgrade inflammation. These changes imply that elderly patients will respond differently to ICI therapy than do younger patients evaluated in clinical trials.

Collectively, age-related changes and alterations in signaling pathways are complex and interconnected. These changes are likely to influence DC, Teff, and Treg pathways, increasing the likelihood of $\mathrm{T}$ cell suppression in the elderly (79). Indeed more research is needed to understand the link between age-related cellular and molecular changes and their potential influence on DC and $\mathrm{T}$ cell pathways leading to the development of autoimmunity. Nonetheless, lessons learned from the oncology field are valuable, enabling researchers to realize that the immune system is capable of reconfiguring the immune checkpoint complex network after modulation using ICIs. The altered expression of inhibitory receptors as seen in vasculitis patients, such as the abnormalities in the PD-1/PD-L1 pathway (105), hints at the involvement of immune checkpoints in disease development. Perhaps the use of agonistic inhibitory checkpoint molecules to halt self-damaging responses could restore the checks and balances, which are reported to be deficient in vasculitis.

\section{ETHICS STATEMENT}

Written informed consent was obtained from the patient prior to presenting the case.

\section{AUTHOR CONTRIBUTIONS}

All authors listed have made a substantial, direct, and intellectual contribution to the work and approved it for publication.

\section{ACKNOWLEDGMENTS}

RC received a Scholarship from the Mexican National Council of Science and Technology (CONACyT), Government of Mexico. We would like to thank Dr. Diane Black for her rigorous proofreading and language editing. We also thank Jacolien Graver for the temporal artery biopsy images.

\section{FUNDING}

This work was supported by RELENT. WA, PH, and EB have received funding from the European Union's Horizon 2020 research and innovation programme under grant agreement No. 668036. The views expressed here are the responsibility of the author(s) only. The EU Commission takes no responsibility for any use made of the information set out. 


\section{REFERENCES}

1. Hodi FS, O'Day SJ, McDermott DF, Weber RW, Sosman JA, Haanen JB, et al. Improved survival with ipilimumab in patients with metastatic melanoma. N Engl J Med (2010) 363(8):711-23. doi:10.1056/NEJMoa1003466

2. Topalian SL, Hodi FS, Brahmer JR, Gettinger SN, Smith DC, McDermott DF, et al. Safety, activity, and immune correlates of anti-PD-1 antibody in cancer. N Engl J Med (2012) 366(26):2443-54. doi:10.1056/NEJMoa1200690

3. Boutros C, Tarhini A, Routier E, Lambotte O, Ladurie FL, Carbonnel F, et al. Safety profiles of anti-CTLA- 4 and anti-PD- 1 antibodies alone and in combination. Nat Rev Clin Oncol (2016) 13(8):473-86. doi:10.1038/nrclinonc.2016.58

4. Michot JM, Bigenwald C, Champiat S, Collins M, Carbonnel F, PostelVinay S, et al. Immune-related adverse events with immune checkpoint blockade: a comprehensive review. Eur J Cancer (2016) 54:139-48. doi:10.1016/ j.ejca.2015.11.016

5. Suarez-Almazor ME, Kim ST, Abdel-Wahab N, Diab A. Review: immunerelated adverse events with use of checkpoint inhibitors for immunotherapy of cancer. Arthritis Rheumatol (2017) 69(4):687-99. doi:10.1002/art.40043

6. June $\mathrm{CH}$, Warshauer JT, Bluestone JA. Is autoimmunity the Achilles' heel of cancer immunotherapy? Nat Med (2017) 23(5):540-7. doi:10.1038/nm.4321

7. van den Brom RRH, Abdulahad WH, Rutgers A, Kroesen B-J, Roozendaal C, de Groot DA, et al. Rapid granulomatosis with polyangiitis induced by immune checkpoint inhibition. Rheumatol Oxf Engl (2016) 55(6):1143-5. doi:10.1093/rheumatology/kew063

8. Minor DR, Bunker SR, Doyle J. Lymphocytic vasculitis of the uterus in a patient with melanoma receiving ipilimumab. J Clin Oncol (2013) 31(20):e356-356. doi:10.1200/JCO.2012.47.5095

9. Goldstein BL, Gedmintas L, Todd DJ. Drug-associated polymyalgia rheumatica/giant cell arteritis occurring in two patients after treatment with ipilimumab, an antagonist of CTLA-4. Arthritis Rheumatol (2014) 66(3): 768-9. doi:10.1002/art.38282

10. Hodi FS, Lawrence D, Lezcano C, Wu X, Zhou J, Sasada T, et al. Bevacizumab plus ipilimumab in patients with metastatic melanoma. Cancer Immunol Res (2014) 2(7):632-42. doi:10.1158/2326-6066.CIR-14-0053

11. Calabrese C, Kirchner E, Kontzias K, Velcheti V, Calabrese LH. Rheumatic immune-related adverse events of checkpoint therapy for cancer: case series of a new nosological entity. RMD Open (2017) 3(1):e000412. doi:10.1136/ rmdopen-2016-000412

12. Alexander $\mathrm{W}$. The checkpoint immunotherapy revolution: what started as a trickle has become a flood, despite some daunting adverse effects; new drugs, indications, and combinations continue to emerge. $P$ T (2016) 41(3):185-91.

13. Hodi SF, O’Day SJ, McDermott DF, Weber RW, Sosman JA, Haanen JB, et al. Improved survival with ipilimumab in patients with metastatic melanoma. N Engl J Med (2010) 363(13):1290. doi:10.1056/NEJMx100063

14. Mahoney KM, Freeman GJ, McDermott DF. The next immune-checkpoint inhibitors: Pd-1/pd-l1 blockade in melanoma. Clin Ther (2015) 37:764-82. doi:10.1016/j.clinthera.2015.02.018

15. Ribas A, Puzanov I, Dummer R, Schadendorf D, Hamid O, Robert C, et al. Pembrolizumab versus investigator-choice chemotherapy for ipilimumabrefractory melanoma (KEYNOTE-002): a randomised, controlled, phase 2 trial. Lancet Oncol (2015) 16(8):908-18. doi:10.1016/S1470-2045(15)00083-2

16. Robert C, Schachter J, Long GV, Arance A, Grob JJ, Mortier L, et al. Pembrolizumab versus ipilimumab in advanced melanoma. $N$ Engl J Med (2015) 372(26):2521-32. doi:10.1056/NEJMoa1503093

17. Weber JS, D’Angelo SP, Minor D, Hodi FS, Gutzmer R, Neyns B, et al. Nivolumab versus chemotherapy in patients with advanced melanoma who progressed after anti-CTLA-4 treatment (CheckMate 037): a randomised, controlled, open-label, phase 3 trial. Lancet Oncol (2015) 16(4):375-84. doi:10.1016/S1470-2045(15)70076-8

18. Rosenberg JE, Hoffman-Censits J, Powles T, Van Der Heijden MS, Balar AV, Necchi A, et al. Atezolizumab in patients with locally advanced and metastatic urothelial carcinoma who have progressed following treatment with platinum-based chemotherapy: a single-arm, multicentre, phase 2 trial. Lancet (2016) 387(10031):1909-20. doi:10.1016/S0140-6736(16)00561-4

19. Blumenthal GM, Pazdur R. Approvals in 2016: the march of the checkpoint inhibitors. Nat Rev Clin Oncol (2017) 14(3):131-2. doi:10.1038/ nrclinonc. 2017.15
20. Postow MA, Chesney J, Pavlick AC, Robert C, Grossmann K, David M, et al. Nivolumab and ipilimumab versus ipilimumab in untreated melanoma. $\mathrm{N}$ Engl J Med (2015) 372(21):2006-17. doi:10.1056/NEJMoa1414428

21. Larkin J, Vanna C-S, Gonzalez R, Grob J, Cowey LC, Lao CD, et al. Combined nivolumab and ipilimumab or monotherapy in untreated melanoma. $N$ Engl $J$ Med (2015) 373(1):23-34. doi:10.1056/NEJMoa1504030

22. Wolchok JD, Hoos A, O’Day S, Weber JS, Hamid O, Lebbe C, et al. Guidelines for the evaluation of immune therapy activity in solid tumors: immune-related response criteria. Clin Cancer Res (2009) 15(23):7412-20. doi:10.1158/10780432.CCR-09-1624

23. Schwartz RH. Costimulation of T lymphocytes: the role of CD28, CTLA-4, and B7/BB1 in interleukin-2 production and immunotherapy. Cell (1992) 71:1065-8. doi:10.1016/S0092-8674(05)80055-8

24. Rudd CE, Taylor A, Schneider H. CD28 and CTLA-4 coreceptor expression and signal transduction. Immunol Rev (2009) 229(1):12-26. doi:10.1111/j.1600-065X.2009.00770.x

25. Pardoll DM. The blockade of immune checkpoints in cancer immunotherapy. Nat Rev Cancer (2012) 12(4):252-64. doi:10.1038/nrc3239

26. Lenschow DJ, Walunas TL, Bluestone JA. CD28/B7 system of T cell costimulation. Annu Rev Immunol (1996) 14(1):233-58. doi:10.1146/annurev. immunol.14.1.233

27. Freeman GJ, Gribben JG, Boussiotis VA, Ng JW, Restivo VA, Lombard LA, et al. Cloning of B7-2: a CTLA- 4 counter-receptor that costimulates human T cell proliferation. Science (1993) 262(5135):909-11. doi:10.1126/science. 7694363

28. Azuma M, Ito D, Yagita H, Okumura K, Phillips JH, Lanier LL, et al. B70 antigen is a second ligand for CTLA-4 and CD28. Nature (1993) 366(6450): 76-9. doi:10.1038/366076a0

29. Parry RV, Chemnitz JM, Frauwirth KA, Lanfranco AR, Braunstein I, Kobayashi SV, et al. CTLA-4 and PD-1 receptors inhibit T-cell activation by distinct mechanisms. Mol Cell Biol (2005) 25(21):9543-53. doi:10.1128/ MCB.25.21.9543-9553.2005

30. Linsley PS, Greene JL, Brady W, Bajorath J, Ledbetter JA, Peach R. Human B7-1 $\{(\mathrm{CD} 80)\}$ and B7-2 $\{(\mathrm{CD} 86)\}$ bind with similar avidities but distinct kinetics to $\{$ CD28\} and $\{$ CTLA-4 $\}$ receptors. Immunity (1994) 1(9):793-801. doi:10.1016/S1074-7613(94)80021-9

31. Schneider H, Downey J, Smith A, Zinselmeyer BH, Rush C, Brewer JM, et al. Reversal of the TCR stop signal by CTLA-4. Sciecne (2006) 313(5795): 1972-5. doi:10.1126/science.1131078

32. Qureshi OS, Zheng Y, Nakamura K, Attridge K, Manzotti C, Schmidt EM, et al. Trans-endocytosis of CD80 and CD86: a molecular basis for the cell-extrinsic function of CTLA-4. Science (2011) 332:600-3. doi:10.1126/science.1202947

33. Grohmann U, Orabona C, Fallarino F, Vacca C, Calcinaro F, Falorni A, et al. CTLA-4-Ig regulates tryptophan catabolism in vivo. Nat Immunol (2002) 3(11):1097-101. doi:10.1038/ni846

34. Uyttenhove C, Pilotte L, Théate I, Stroobant V, Colau D, Parmentier N, et al. Evidence for a tumoral immune resistance mechanism based on tryptophan degradation by indoleamine 2,3-dioxygenase. Nat Med (2003) 9(10): 1269-74. doi:10.1038/nm934

35. Peggs KS, Quezada SA, Chambers CA, Korman AJ, Allison JP. Blockade of \{CTLA-4\} on both effector and regulatory T cell compartments contributes to the antitumor activity of \{anti-CTLA-4\} antibodies. JExp Med (2009) 206(8):1717-25. doi:10.1084/jem.20082492

36. Fallarino F, Grohmann U, Hwang KW, Orabona C, Vacca C, Bianchi R, et al. Modulation of tryptophan catabolism by regulatory T cells. Nat Immunol (2003) 4(12):1206-12. doi:10.1038/ni1003

37. Postow MA, Callahan MK, Wolchok JD. Immune checkpoint blockade in cancer therapy. JClin Oncol (2015) 33(17):1974-82. doi:10.1200/ JCO.2014.59.4358

38. Bardhan K, Patsoukis N, Weaver J, Freeman G, Li L, Boussiotis VA. PD-1 inhibits the TCR signaling cascade by sequestering SHP-2 phosphatase, preventing its translocation to lipid rafts and facilitating Csk-mediated inhibitory phosphorylation of Lck. J Immunol (2016) 196(1 Suppl):128.15L-128.15.

39. Baumeister SH, Freeman GJ, Dranoff G, Sharpe AH. Coinhibitory pathways in immunotherapy for cancer. Annu Rev Immunol (2016) 34:539-73. doi:10.1146/ annurev-immunol-032414-112049

40. Freeman GJ, Long AJ, Iwai $\mathrm{Y}$, Bourque $\mathrm{K}$, Chernova T, Nishimura $\mathrm{H}$, et al. Engagement of the PD-1 immunoinhibitory receptor by a novel B7 family 
member leads to negative regulation of lymphocyte activation. J Exp Med (2000) 192(7):1027-34. doi:10.1084/jem.192.7.1027

41. Keir ME, Butte MJ, Freeman GJ, Sharpe AH. PD-1 and its ligands in tolerance and immunity. Annu Rev Immunol (2008) 26(1):677-704. doi:10.1146/ annurev.immunol.26.021607.090331

42. Riley JL. PD-1 signaling in primary T cells. Immunol Rev (2009) 229:114-25. doi:10.1111/j.1600-065X.2009.00767.x

43. Francisco LM, Sage PT, Sharpe AH. The PD-1 pathway in tolerance and autoimmunity. Immunol Rev (2010) 236:219-42. doi:10.1111/j.1600-065X. 2010.00923.x

44. Terme M, Ullrich E, Aymeric L, Meinhardt K, Desbois M, Delahaye N, et al. IL-18 induces PD-1-dependent immunosuppression in cancer. Cancer Res (2011) 71(16):5393-9. doi:10.1158/0008-5472.CAN-11-0993

45. Francisco LM, Salinas VH, Brown KE, Vanguri VK, Freeman GJ, Kuchroo VK, et al. PD-L1 regulates the development, maintenance, and function of induced regulatory T cells. J Exp Med (2009) 206(13):3015-29. doi:10.1084/ jem.20090847

46. Keir ME, Liang SC, Guleria I, Latchman YE, Qipo A, Albacker LA, et al. Tissue expression of PD-L1 mediates peripheral T cell tolerance. J Exp Med (2006) 203(4):883-95. doi:10.1084/jem.20051776

47. Blank C, Brown I, Peterson AC, Spiotto M, Iwai Y, Honjo T, et al. PD-L1/ B7H-1 inhibits the effector phase of tumor rejection by $\mathrm{T}$ cell receptor (TCR) transgenic CD8+ T cells. Cancer Res (2004) 64(3):1140-5. doi:10.1158/00085472.CAN-03-3259

48. Okazaki T, Chikuma S, Iwai Y, Fagarasan S, Honjo T. A rheostat for immune responses: the unique properties of PD-1 and their advantages for clinical application. Nat Immunol (2013) 14(12):1212-8. doi:10.1038/ni.2762

49. Chen DS, Mellman I. Oncology meets immunology: the cancer-immunity cycle. Immunity (2013) 39:1-10. doi:10.1016/j.immuni.2013.07.012

50. Swart M, Verbrugge I, Beltman JB. Combination approaches with immune-checkpoint blockade in cancer therapy. Front Oncol (2016) 6:233. doi:10.3389/fonc.2016.00233

51. Cha E, Klinger M, Hou Y, Cummings C, Ribas A, Faham M, et al. Improved survival with $\mathrm{T}$ cell clonotype stability after anti-CTLA-4 treatment in cancer patients. Sci Transl Med (2014) 6(238):238ra70. doi:10.1126/ scitranslmed.3008211

52. Simpson TR, Li F, Montalvo-Ortiz W, Sepulveda MA, Bergerhoff K, Arce F, et al. Fc-dependent depletion of tumor-infiltrating regulatory $\mathrm{T}$ cells codefines the efficacy of anti-CTLA-4 therapy against melanoma. J Exp Med (2013) 210(9):1695-710. doi:10.1084/jem.20130579

53. Selby MJ, Engelhardt JJ, Quigley M, Henning KA, Chen T, Srinivasan M, et al. Anti-CTLA-4 antibodies of IgG2a isotype enhance antitumor activity through reduction of intratumoral regulatory T cells. Cancer Immunol Res (2013) 1(1):32-42. doi:10.1158/2326-6066.CIR-13-0013

54. Bettelli E, Oukka M, Kuchroo VK. T(H)-17 cells in the circle of immunity and autoimmunity. Nat Immunol (2007) 8(4):345-50. doi:10.1038/ni0407-345

55. Muranski P, Boni A, Antony PA, Cassard L, Irvine KR, Kaiser A, et al. Tumorspecific Th17-polarized cells eradicate large established melanoma. Blood (2008) 112(2):362-73. doi:10.1182/blood-2007-11-120998

56. von Euw E, Chodon T, Attar N, Jalil J, Koya RC, Comin-Anduix B, et al. CTLA4 blockade increases Th17 cells in patients with metastatic melanoma. J Transl Med (2009) 7:35. doi:10.1186/1479-5876-7-35

57. Wei SC, Levine JH, Cogdill AP, Wargo JA, Pe'er D, Allison JP. Distinct Cellular Mechanisms Underlie Anti-CTLA-4 and Anti-PD-1 Checkpoint Blockade. (2017). Available from: http://www.cell.com/cell/pdf/S0092-8674(17)30831-0. pdf

58. Liakou CI, Kamat A, Tang DN, Chen H, Sun J, Troncoso P, et al. CTLA-4 blockade increases IFNgamma-producing CD4+ICOShi cells to shift the ratio of effector to regulatory T cells in cancer patients. Proc Natl Acad Sci U S A (2008) 105(39):14987-92. doi:10.1073/pnas.0806075105

59. Ng Tang D, Shen Y, Sun J, Wen S, Wolchok JD, Yuan J, et al. Increased frequency of ICOS+ CD4 T cells as a pharmacodynamic biomarker for anti-CTLA-4 therapy. Cancer Immunol Res (2013) 1(4):229-34. doi:10.1158/2326-6066. CIR-13-0020

60. Koyama S, Akbay EA, Li YY, Herter-Sprie GS, Buczkowski KA, Richards WG, et al. Adaptive resistance to therapeutic PD-1 blockade is associated with upregulation of alternative immune checkpoints. Nat Commun (2016) 7:1-9. doi:10.1038/ncomms10501
61. Huang R-Y, Francois A, McGray AR, Miliotto A, Odunsi K. Compensatory upregulation of PD-1, LAG-3, and CTLA-4 limits the efficacy of single-agent checkpoint blockade in metastatic ovarian cancer. Oncoimmunology (2017) 6(1):e1249561. doi:10.1080/2162402X.2016.1249561

62. Gao J, Ward JF, Pettaway CA, Shi LZ, Subudhi SK, Vence LM, et al. VISTA is an inhibitory immune checkpoint that is increased after ipilimumab therapy in patients with prostate cancer. Nat Med (2017) 23:551-5. doi:10.1038/nm. 4308

63. Gao J, Ward JF, Pettaway CA, Shi LZ, Subudhi SK, Vence LM, et al. VISTA upregulation may promote resistance to CTLA-4 blockade. Cancer Discov (2017) 7(6):OF15. doi:10.1158/2159-8290.CD-RW2017-069

64. Kamphorst AO, Wieland A, Nasti T, Yang S, Zhang R, Barber DL, et al. Rescue of exhausted CD8 T cells by PD-1-targeted therapies is CD28-dependent. Science (2017) 1427(March):1423-7. doi:10.1126/science.aaf0683

65. Hui E, Cheung J, Zhu J, Su X, Taylor MJ, Wallweber HA, et al. T cell costimulatory receptor $\mathrm{CD} 28$ is a primary target for PD-1-mediated inhibition. Science (2017) 355(6332):1428-33. doi:10.1126/science.aaf1292

66. Krueger J, Rudd CE. Two strings in one bow: PD-1 negatively regulates via co-receptor CD28 on T cells. Immunity (2017) 46:529-31. doi:10.1016/j. immuni.2017.04.003

67. Nordkamp M, Koeleman BP, Meyaard L. Do inhibitory immune receptors play a role in the etiology of autoimmune disease? Clin Immunol (2014) 150(1):31-42. doi:10.1016/j.clim.2013.11.007

68. Ceeraz S, Nowak EC, Burns CM, Noelle RJ. Immune checkpoint receptors in regulating immune reactivity in rheumatic disease. Arthritis Res Ther (2014) 16(5):469. doi:10.1186/s13075-014-0469-1

69. van der Vlist M, Kuball J, Radstake TRD, Meyaard L. Immune checkpoints and rheumatic diseases: what can cancer immunotherapy teach us? Nat Rev Rheumatol (2016) 12(10):593-604. doi:10.1038/nrrheum.2016.131

70. Boots AMH, Maier AB, Stinissen P, Masson P, Lories RJ, De Keyser F. The influence of ageing on the development and management of rheumatoid arthritis. Nat Rev Rheumatol (2013) 9(10):604-13. doi:10.1038/nrrheum. 2013.92

71. Weng NP, Akbar AN, Goronzy J. CD28- T cells: their role in the age-associated decline of immune function. Trends Immunol (2009) 30:306-12. doi:10.1016/ j.it.2009.03.013

72. Boraschi D, Aguado MT, Dutel C, Goronzy J, Louis J, Grubeck-Loebenstein B, et al. The gracefully aging immune system. Sci Transl Med (2013) 5(185): 185s8. doi:10.1126/scitranslmed.3005624

73. 'T Hart BA, Chalan P, Koopman G, Boots AMH. Chronic autoimmunemediated inflammation: a senescent immune response to injury. Drug Discov Today (2013) 18:372-9. doi:10.1016/j.drudis.2012.11.010

74. Linton PJ, Dorshkind K. Age-related changes in lymphocyte development and function. Nat Immunol (2004) 5(2):133-9. doi:10.1038/ni1033

75. Weinberger B, Lazuardi L, Weiskirchner I, Keller M, Neuner C, Fischer KH, et al. Healthy aging and latent infection with CMV lead to distinct changes in CD8+ and CD4+ T-cell subsets in the elderly. Hum Immunol (2007) 68(2):86-90. doi:10.1016/j.humimm.2006.10.019

76. Moro-García MA, Alonso-Arias R, López-Larrea C. When aging reaches CD4+ T-cells: phenotypic and functional changes. Front Immunol (2013) 4:107. doi:10.3389/fimmu.2013.00107

77. Amyes E, Hatton C, Montamat-Sicotte D, Gudgeon N, Rickinson AB, McMichael AJ, et al. Characterization of the CD4+ T cell response to Epstein-Barr virus during primary and persistent infection. J Exp Med (2003) 198(6):903-11. doi:10.1084/jem.20022058

78. Broux B, Markovic-Plese S, Stinissen P, Hellings N. Pathogenic features of CD4+CD28- T cells in immune disorders. Trends Mol Med (2012) 18:446-53. doi:10.1016/j.molmed.2012.06.003

79. Gardner JK, Mamotte CDS, Jackaman C, Nelson DJ. Modulation of dendritic cell and $\mathrm{T}$ cell cross-talk during aging: the potential role of checkpoint inhibitory molecules. Ageing Res Rev (2017) 38:40-51. doi:10.1016/j. arr.2017.07.002

80. Leng Q, Bentwich Z, Borkow G. CTLA-4 upregulation during aging. Mech Ageing Dev (2002) 123(10):1419-21. doi:10.1016/S0047-6374(02)00077-5

81. Sakuishi K, Apetoh L, Sullivan JM, Blazar BR, Kuchroo VK, Anderson AC. Targeting Tim-3 and PD-1 pathways to reverse $\mathrm{T}$ cell exhaustion and restore anti-tumor immunity. J Exp Med (2010) 207(10):2187-94. doi:10.1084/ jem.20100643 
82. Jin H-T, Anderson AC, Tan WG, West EE, Ha S-J, Araki K, et al. Cooperation of Tim-3 and PD-1 in CD8 T-cell exhaustion during chronic viral infection. Proc Natl Acad Sci U S A (2010) 107(33):14733-8. doi:10.1073/pnas. 1009731107

83. Barber DL, Wherry EJ, Masopust D, Zhu B, Allison JP, Sharpe AH, et al. Restoring function in exhausted CD8 $\mathrm{T}$ cells during chronic viral infection. Nature (2006) 439(7077):682-7. doi:10.1038/nature04444

84. Vallejo AN, Weyand CM, Goronzy JJ. T-cell senescence: a culprit of immune abnormalities in chronic inflammation and persistent infection. Trends Mol Med (2004) 10:119-24. doi:10.1016/j.molmed.2004.01.002

85. Daste A, Domblides C, Gross-goupil M, Chakiba C, Quivy A, Cochin V, et al. Immune checkpoint inhibitors and elderly people: a review. Eur J Cancer (2017) 82:155-66. doi:10.1016/j.ejca.2017.05.044

86. Bürkle A, Caselli G, Franceschi C, Mariani E, Sansoni P, Santoni A, et al. Pathophysiology of ageing, longevity and age related diseases. Immun Ageing (2007) 4:4. doi:10.1186/1742-4933-4-4

87. Campisi J. The biology of replicative senescence. Eur J Cancer A (1997) 33:703-9. doi:10.1016/S0959-8049(96)00058-5

88. Vasto S, Colonna-Romano G, Larbi A, Wikby A, Caruso C, Pawelec G. Role of persistent $\mathrm{CMV}$ infection in configuring $\mathrm{T}$ cell immunity in the elderly. Immun Ageing (2007) 4:2. doi:10.1186/1742-4933-4-2

89. Lintermans LL, Stegeman CA, Heeringa P, Abdulahad WH. T cells in vascular inflammatory diseases. Front Immunol (2014) 5:504. doi:10.3389/ fimmu.2014.00504

90. Jennette JC, Falk RJ, Bacon PA, Basu N. 2012 Revised International Chapel Hill Consensus Conference Nomenclature of vasculitides. Arthritis Rheum (2013) 65(1):1-11. doi:10.1002/art.37715

91. Weiner SR, Paulus HE, Weisbart RH. Wegener's granulomatosis in the elderly. Arthritis Rheum (1986) 29(9):1157-9. doi:10.1002/art.1780290915

92. Watts RA, Carruthers DM, Scott DGI. Epidemiology of systemic vasculitis: changing incidence or definition? Semin Arthritis Rheum (1995) 25(1): 28-34. doi:10.1016/S0049-0172(95)80015-8

93. Watts RA, Al-Taiar A, Scott DGI, Macgregor AJ. Prevalence and incidence of Wegener's granulomatosis in the UK general practice research database. Arthritis Rheum (2009) 61(10):1412-6. doi:10.1002/art.24544

94. Jennette JC, Falk RJ, Hu P, Xiao H. Pathogenesis of antineutrophil cytoplasmic autoantibody-associated small-vessel vasculitis. Annu Rev Pathol Mech Dis (2013) 8(1):139-60. doi:10.1146/annurev-pathol-011811132453

95. Kallenberg CGM, Stegeman CA, Abdulahad WH, Heeringa P. Pathogenesis of ANCA-associated vasculitis: new possibilities for intervention. Am J Kidney Dis (2013) 62(6):1176-87. doi:10.1053/j.ajkd.2013.05.009

96. Wilde B, Hua F, Dolff S, Jun C, Cai X, Specker C, et al. Aberrant expression of the negative costimulator $\{\mathrm{PD}-1\}$ on T cells in granulomatosis with polyangiitis. Rheumatology (2012) 51(7):1188-97. doi:10.1093/rheumatology/ kes034

97. Slot MC, Sokolowska MG, Savelkouls KG, Janssen RGJH, Damoiseaux JGMC, Cohen Tervaert JW. Immunoregulatory gene polymorphisms are associated with ANCA-related vasculitis. Clin Immunol (2008) 128(1):39-45. doi:10.1016/j.clim.2008.03.506
98. Salvarani C, Cantini F, Hunder GG. Polymyalgia rheumatica and giant-cell arteritis. Lancet (2008) 372(9634):234-45. doi:10.1016/S01406736(08)61077-6

99. Samson M, Corbera-Bellalta M, Audia S, Planas-Rigol E, Martin L, Cid MC, et al. Recent advances in our understanding of giant cell arteritis pathogenesis. Autoimmun Rev (2017) 16(8):833-44. doi:10.1016/j.autrev.2017.05.014

100. Dejaco C, Brouwer E, Mason JC, Buttgereit F, Matteson EL, Dasgupta B. Giant cell arteritis and polymyalgia rheumatica: current challenges and opportunities. Nat Rev Rheumatol (2017) 13(10):578-92. doi:10.1038/ nrrheum.2017.142

101. Langford CA, Cuthbertson D, Ytterberg SR, Khalidi N, Monach PA, Carette S, et al. A randomized, double-blind trial of abatacept (CTLA-4Ig) for the treatment of giant cell arteritis. Arthritis Rheumatol (2017) 69(4):837-45. doi:10.1002/art.40044

102. Garber K. Make or break for costimulatory blockers. Nat Biotechnol (2004) 22(2):145-7. doi:10.1038/nbt0304-341c

103. Dulos J, Carven GJ, van Boxtel SJ, Evers S, Driessen-Engels LJA, Hobo W, et al. PD-1 blockade augments Th1 and Th17 and suppresses Th 2 responses in peripheral blood from patients with prostate and advanced melanoma cancer. J Immunother (2012) 35(2):169-78. doi:10.1097/CJI.0b013e318247a4e7

104. Zhang H, Watanabe R, Berry GJ, Vaglio A, Liao YJ, Warrington KJ, et al. Immunoinhibitory checkpoint deficiency in medium and large vessel vasculitis. Proc Natl Acad Sci U S A (2017) 114(6):E970-9. doi:10.1073/ pnas. 1616848114

105. Weyand CM, Berry GJ, Goronzy JJ. The immunoinhibitory PD-1/PD-L1 pathway in inflammatory blood vessel disease. JLeukoc Biol (2017). doi:10.1189/jlb.3MA0717-283

106. Weyand CM, Younge BR, Goronzy JJ. IFN- $\gamma$ and IL-17: the two faces of T-cell pathology in giant cell arteritis. Curr Opin Rheumatol (2011) 23(1):43-9. doi:10.1097/BOR.0b013e32833ee946

107. Terrier B, Geri G, Chaara W, Allenbach Y, Rosenzwajg M, CostedoatChalumeau N, et al. Interleukin-21 modulates Th1 and Th17 responses in giant cell arteritis. Arthritis Rheum (2012) 64(6):2001-11. doi:10.1002/ art. 34327

108. CrowsonCS,MattesonEL,MyasoedovaE, MichetCJ,ErnsteFC, WarringtonKJ, et al. The lifetime risk of adult-onset rheumatoid arthritis and other inflammatory autoimmune rheumatic diseases. Arthritis Rheum (2011) 63(3):633-9. doi:10.1002/art.30155

Conflict of Interest Statement: The authors declare that the research was conducted in the absence of any commercial or financial relationships that could be construed as a potential conflict of interest.

Copyright $\odot 2018$ Hid Cadena, Abdulahad, Hospers, Wind, Boots, Heeringa and Brouwer. This is an open-access article distributed under the terms of the Creative Commons Attribution License (CC BY). The use, distribution or reproduction in other forums is permitted, provided the original author(s) and the copyright owner are credited and that the original publication in this journal is cited, in accordance with accepted academic practice. No use, distribution or reproduction is permitted which does not comply with these terms. 